Brit. J. industr. Med., 1962, 19, 229.

\title{
PROTECTIVE CLOTHING AS A FACTOR IN THE DUST HAZARD OF POTTERS
}

\author{
BY \\ W. A. BLOOR and A. DINSDALE \\ From The British Ceramic Research Association, Stoke-on-Trent
}

(RECEIVED FOR PUBLICATION FEBRUARY 2, 1962)

\begin{abstract}
Investigations into the factors affecting dust concentrations in the breathing zone of pottery operatives have shown that cotton overalls constitute a serious source of dust. Attempts to overcome this difficulty by treatment of the material were not successful, so other types of materials were investigated. Terylene was found to have outstandingly desirable properties; types of "terylene" material and designs of clothing were defined. Factory tests showed that with this new protective clothing reductions of up to $65 \%$ in breathing zone dust concentrations were achieved. This type of clothing is now being officially recommended by the Joint Standing Committee for the Pottery Industry.
\end{abstract}

The Pottery (Health and Welfare) Special Regulations, 1950, require the factory occupier to provide protective clothing of suitable design and material for all persons employed in certain processes, and every person employed in these processes is required to wear the clothing provided. The items of clothing specified include washable overalls and aprons. The factory occupier is required to have the overalls and aprons washed or renewed weekly. The obvious intention of these Regulations is to help in the general suppression of dust and to prevent the contamination of the operative's normal clothing by dust or moisture or both.

During investigations of dusty processes in the pottery industry it became apparent that the good intentions of the Regulations were not being achieved. It was found that the protective overalls and aprons being worn were themselves serious sources of fine respirable-size dust. In view of the obvious importance of this aspect of dust suppression, protective clothing has been the subject of a separate investigation.

This paper describes the results of this work, and it may be of help in other industries where dust hazards exist and where clothing may be an important element in the problem.

\section{Investigation of Cotton Fabric}

In the past, the type of fabric most commonly used for washable overalls and aprons in the pottery industry was a medium or heavy cotton drill.
When it was suspected that this material was responsible for high dust concentrations it was decided to seek quantitative evidence under factory conditions. Tests were carried out in a sanitary whiteware casting shop in which the operatives were fettling and sponging moist clay-ware, in itself a dust-free operation. Half the number of pieces of ware were processed while the operative was wearing one set of protective clothing, and the remaining half while wearing another set. In this way the effect of factors other than clothing could be expected to remain reasonably constant and any significant difference in dust concentrations in the operative's breathing zone could be attributed to the changes made in the clothing. Dust samples were taken in the operative's breathing zone by strapping a thermal precipitator sampling-head to the chest. Samples were taken at the same time in the general atmosphere of the workroom in the vicinity of the operative. The results of these tests showed that changing from a dusty cotton overall to a clean one could reduce the mean dust concentration in the operative's breathing zone by as much as $65 \%$. From these tests it became clear that dusty overalls could contribute significantly to the dust concentrations to which these pottery operatives were exposed.

It is of interest to consider how the dust concentrations may be influenced by the nature of the fabric. There are many ways in which overalls get dusty; the more obvious are by contact with dusty objects and materials, by contact with dry clay-ware, or by 


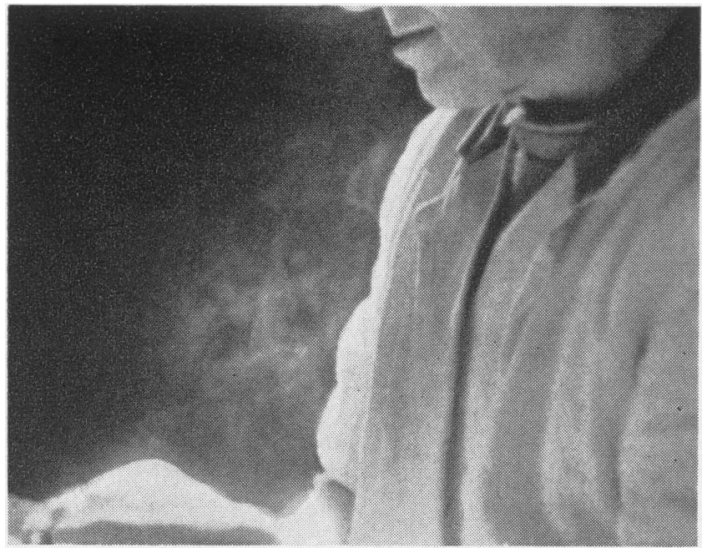

FIG. 1.-Dust moving up into breathing zone from worker's overall.

picking up wet clay-ware that subsequently dries to produce dust. Cotton appears to have a very high capacity for picking up dust. Further, having picked it up, it releases it again when subjected to knocks or slight movement. The dust thus released is often carried up into the breathing zone of the wearer by the air convection currents induced by the warmth of the body (Fig. 1).

It follows from these considerations that for an overall fabric to be suitable it is important that when it comes into contact with loose dust, or with clayware, either the amount of material transferred to the fabric should be very small, or the amount transferred should not easily be released again. In order to find a fabric that fulfilled these conditions, there seemed to be two possible approaches-either to subject the cotton to some form of treatment, or to seek new materials. The particular feature of cotton drill that causes it to pick up dust is the hairy nature of the surface, and any treatment which reduces the hairiness could be expected to improve its dust properties. The industrial surface finishes such as glazing and proofing reduce the hairiness considerably. However, such treatment cannot be considered permanent or renewable in overalls which may get rough usage and which are required to be laundered weekly.

An alternative to reducing the hairiness of cotton would be to treat it in some way so that any dust coming into contact with it would be securely held. Van den Ende and Thomas (1941) showed that the application of small amounts of oil to cotton fabrics acted in this way and greatly reduced the dissemination of dust from them. The amount of oil used was below the level at which the fabric became oily to the touch.
The method of applying the oil recommended by Harwood, Powney, and Edwards (1944) was found to be both easy and effective. In this method two small quantities of white oil are used in the form of positively- and negatively-charged emulsions. The two emulsions are merely added to the final rinsing water during laundering and the oil is completely discharged onto the fabric. The method is cheap and applicable on a large scale.

The laboratory and factory trials showed that this oiling method is very effective up to a point. Fine dust coming into contact with the fabric is held by the oil and not easily dislodged again. There is, of course, a limit to the amount of dust that can be held in this way. The factory trials of oiled cotton drill showed that with some of the more dusty pottery processes the dust saturation point might be reached after only two days' wear. After that, the oil had little or no effect. In view of this, no further work was done on these lines, and it was decided to look into the possibilities of new types of material.

\section{Investigation of Other Fabrics}

Because of the many ways in which overalls may acquire dust in factory use there are obvious difficulties in simulating actual conditions by means of laboratory tests. However, as contact with loose clay dust and with dry clay-ware appeared to be the two principal means of contamination two simple laboratory tests were devised with which to compare different materials.

In the first one, pieces of the fabric about 1 in. square were tumbled with a quantity of fine dry clay dust in a rotating jar (Fig. 2). The dust consisted of a dried earthenware "body", through 200 mesh, and containing about $50 \%$ clay and $30 \%$ free silica. The pieces were then transferred to a perforated cylinder and gently rotated again to remove dust that was merely lying on, but not actually adhering to, the surface. The amount of dust held by the fabric after this treatment was determined by igniting the fabric samples and weighing the residue.

In the second apparatus (Fig. 3) a strip of the fabric about $1 \mathrm{in}$. wide was attached to the periphery of a slowly rotating wheel. During the rotation of the wheel the fabric was in rubbing contact with a block of dry clay-ware resting lightly upon it. At the end of the test the weight of dust retained by the fabric was determined. The results of tests on different fabrics, including the cotton drill in common use, are given in Table 1.

The one feature common to all the fabrics that gave the best performance in the tumbling test was the absence of surface hairs. The various satins with their smooth surfaces gave good results, but 


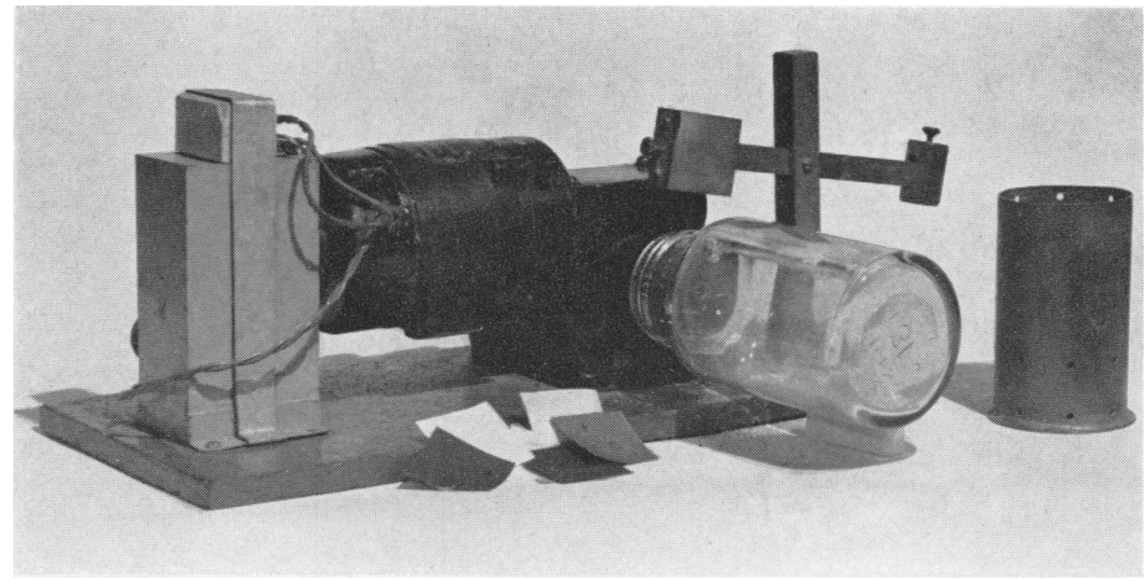

Fig. 2.-Tumbling test apparatus.

other features are also required in the ideal overall fabric. It must be durable, not easily torn, comfortable to wear, and must stand up to weekly laundering. With these requirements in mind five of the fabrics were selected to be made up into overalls for factory trials. The selected fabrics, marked with an asterisk in Table 1, are specified qualities and constructions of "fortisan", acetate rayon, "viscose duracol", nylon, and "terylene". Thirty overalls were made up from these five fabrics and distributed to 11 factories.

During these trials, all but one of the materials retained the special dust properties for which they had been chosen. The exception was the fortisan material which deteriorated rapidly during laundering and was no improvement on cotton.
The other four materials appeared clean and relatively dust-free after each week's wear and the operatives themselves volunteered the opinion that they "resisted" the dust. The most difficult characteristic to assess was that of comfort. It depends on the fit of the overall, on the environment, and on the individual.

The final assessment of the five trial fabrics after being in use for periods of up to two years is given in Table 2.

The outstanding material was terylene, since after more than two years all the overalls in this material were still in good condition. Initial cost is higher than cotton, but they last much longer and laundering costs should be lower since they do not need boiling or ironing.

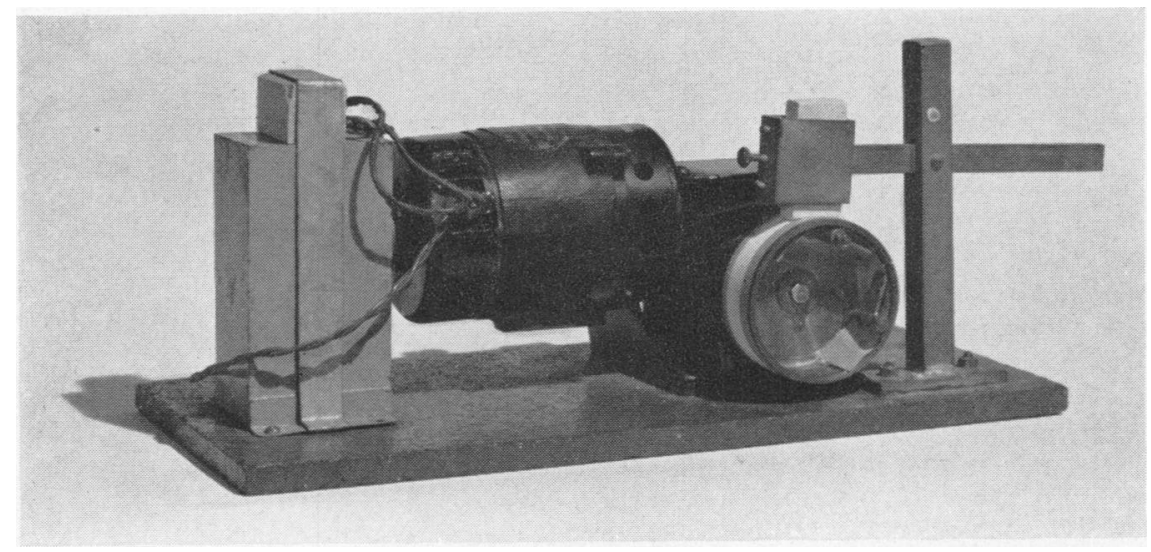

FIG. 3.-Rubbing test apparatus. 
TABLE 1

RESULTS OF DUST-RETENTION TESTS ON FABRICS

\begin{tabular}{|c|c|c|}
\hline \multirow{2}{*}{ Fabric } & \multicolumn{2}{|c|}{$\begin{array}{l}\text { Weight of Dust (g.) Retained } \\
\text { on Fabric }\end{array}$} \\
\hline & Tumbling Test & Rubbing Test \\
\hline $\begin{array}{l}\text { Acetate satin } \\
\text { Downproof cotton sateen } \\
\text { Nylon/acetate satin } \\
\text { Viscose/cotton satin } \\
\text { Acetate satin } \\
\text { Pure silk satin } \\
\text { Terylene: } \\
\text { Filament } 71 \text { oz.* } \\
\text { Silicone finish } 7 \frac{1}{2} \text { oz. } \\
\text { Silicone finish } 4 \text { oz. }^{\circ} \\
\text { Viscose duracol* } \\
\text { Acetate rayon* } \\
\text { Fortisan* } \\
\text { Nylon* } \\
\text { Fibroduracol: } \\
6 \text { oz. } \\
\text { Heavy } \\
7 \frac{1}{2} \text { oz. } \\
9 \text { oz. } \\
\text { Everglaze cotton } \\
\text { Cotton/nylon } \\
\text { Cotton dril fabric: } \\
\text { In common use } \\
\text { In common use } \\
\text { Burma green cotton } \\
\text { Velan drab cotton } \\
\text { Oxford weave cotton } \\
\text { Thermovyl/fibrovyl/nylon }\end{array}$ & $\begin{array}{l}0.014 \\
0.023 \\
0.025 \\
0.029 \\
0.030 \\
0.040 \\
0.020 \\
0.027 \\
0.030 \\
0.020 \\
0.020 \\
0.030 \\
0.045 \\
0.055 \\
0.060 \\
0.079 \\
0.080 \\
0.055 \\
0.090 \\
0.097 \\
0.100 \\
0.100 \\
0.135 \\
0.120 \\
0.145\end{array}$ & $\begin{array}{l}0 \cdot 170 \\
0 \cdot 200 \\
0 \cdot 170 \\
0 \cdot 160 \\
0 \cdot 115 \\
0 \cdot 130 \\
\\
0 \cdot 105 \\
0 \cdot 165 \\
0 \cdot 115 \\
0 \cdot 190 \\
0 \cdot 260 \\
0 \cdot 245 \\
0 \cdot 170 \\
0 \cdot 315 \\
0 \cdot 370 \\
0 \cdot 250 \\
0 \cdot 310 \\
0 \cdot 180 \\
0 \cdot 240\end{array}$ \\
\hline
\end{tabular}

*Fabrics selected for field trials.

TABLE 2

ASSESSMENT OF FIELD TRIAL MATERIALS

\begin{tabular}{|c|c|c|c|c|}
\hline \multirow{2}{*}{ Material } & \multirow{2}{*}{ Laundering } & \multirow{2}{*}{ Durability } & \multicolumn{2}{|c|}{ Comfort } \\
\hline & & & Men & Women \\
\hline $\begin{array}{l}\text { Nylon } \\
\text { Fortisan } \\
\text { Terylene } \\
\text { Acetate rayon } \\
\text { Viscose duracol }\end{array}$ & $\begin{array}{c}\text { Excellent } \\
\text { Deteriorates } \\
\text { Excellent } \\
\text { Fair (shrinks) } \\
\text { Fair (shrinks) }\end{array}$ & $\begin{array}{c}\text { Excellent } \\
\text { Good } \\
\text { Excellent } \\
\text { Good } \\
\text { Good }\end{array}$ & \begin{tabular}{|c|} 
Poor \\
Good \\
Very good \\
Very good \\
Very good
\end{tabular} & $\begin{array}{c}\text { Poor } \\
\text { Good } \\
\text { Very good } \\
\text { Very good } \\
\text { Very good }\end{array}$ \\
\hline
\end{tabular}

\section{Recommended Fabrics and Designs}

As a result of the investigations described in the previous section, it was decided to concentrate attention on terylene in all subsequent work. It is now clear that in this context it is essential that the terylene should be woven from $100 \%$ filament yarn; mixtures with other materials such as cotton or wool are unsuitable. Over 70 different terylene filament fabrics have been tested and while all have a very low dust "pick-up" they differ in their resistance to dust penetration and in their resistance to the passage of air. The ideal fabric would have a high resistance to the passage of dust so as to avoid contamination of underclothing, and a low resistance to the passage of air so as to facilitate ventilation. In a non-hairy fabric such as filament terylene these two properties are incompatible. It is therefore necessary to accept fabrics that represent a compromise between these requirements and which are, in fact, inferior to cotton drill in both respects. On the basis of the results of practical trials of terylene fabrics having big differences in "openness" of weave, simple laboratory tests have been devised which will distinguish between suitable and unsuitable fabrics. In the first of these tests, air is passed at the rate of 30 litres per minute through a 2-in. diameter test piece, and the pressure drop across the fabric is measured. This pressure drop should not be more than about $50 \mathrm{~cm}$. of water. In the other test, $5 \mathrm{~g}$. of a standard dust are placed on a 2-in. diameter test piece of the fabric, which is then mechanically vibrated. The amount of dust passing through should be less than $1 \mathrm{~g}$. Although this specification is in some respects quite arbitrary, it has been drawn up on the basis of the observed performance of a number of fabrics in use under industrial conditions.

Having defined the quality of the material to be used, it was necessary also to consider the question of design. It was clear that in the conventional designs there were some very undesirable features. At the front of the garment there were often pockets and pleats, which retain dust, and openings and buttonholes which let dust through. Designs have therefore been developed that eliminate all these drawbacks and in which an essential feature is a plain front. Designs that have now been officially recommended to the pottery industry as being suitable are shown in Figs. 4 and 5. Modifications to these basic designs are permissible, so long as the plain front is retained, and complete coverage of the worker's own clothing is ensured.

\section{Factory Tests with Recommended Fabrics}

Having decided on suitable materials and designs it was necessary finally to establish under working conditions that dust concentrations could be reduced by wearing this type of protective clothing.

Two series of tests were made in potters' shops in which the dust concentrations in the breathing zone of operatives were measured whilst they were wearing either cotton or terylene overalls.

Sanitary Casters. - The first series of tests was done in a sanitary whiteware casting shop in which there were six operatives. It was possible to classify these operatives according to the normal working state of their overalls as very dirty, dirty, or clean workers. Three of these operatives, one fromeach classification, wore cotton overalls during the first week of the tests and terylene overalls during the second week. In each case they were given a clean overall on Monday mornings. On Tuesday and Friday of each week, after the overalls had been worn for one and 
four days respectively, thermal precipitator dust samples were taken in the breathing zone of each operative during the period when they were fettling and sponging moist clay-ware which is a dust-free operation. At the same time two thermal precipitators were used to take samples of the dust in the general atmosphere of the shop in the vicinity of each operative. Observation and cinephotography of these operatives at work under a Tyndall-beam type of lighting showed that, with the exception of very small amounts of dust from hands and arms and from the handles of tools, there were no local sources other than clothing. The cotton overalls were seen to be prolific and almost continuous sources of dust, this dust having come in the first instance either from contact with the ware during the fettling process, or from work done by the operative when carrying out other operations at other times. This was particularly noticeable in the two operatives classed as dirty workers. With terylene overalls observations for the whole of the sampling period showed only very occasional puffs of dust.

An analysis of the detailed dust samples taken showed that cotton overalls were a serious source of dust after only one day's wear. Although, for the purpose of this experiment, dust concentrations were only measured during a particular period of the day when the casters were performing a dust-free operation, it is obvious that overalls were contributing to the dust concentrations for most of their working time. Indeed, when wearing cotton, overalls probably represent the most important single factor in the dust exposure of these operatives. The relative merits of cotton and terylene can best be judged by gathering together the means of all the observations as shown in Table 3 . It will be seen that when terylene was used, the dust concentrations in the breathing zone of the three types of operatives were reduced by 82,65 , and $52 \%$ respectively.

Earthenware Makers.-The primary purpose of the second series of tests was to determine the dust exposure of operatives making earthenware from a plastic clay body, but opportunity was also taken to obtain information about the effect of clothing in these circumstances.

TABLE 3

MEAN BREATHING ZONE DUST CONCENTRATIONS FOR OPERATIVES WEARING COTTON OR TERYLENE PROTECTIVE CLOTHING

(particles per $\mathrm{cm}^{3}$. in the size range 0.5 to $5.0 \mu$ )

\begin{tabular}{l|c|c}
\hline Operative & Cotton & Terylene \\
\hline Classification & & 48 \\
\hline Very dirty & 262 & 49 \\
Dirty & 142 & 42 \\
Clean & 88 & \\
\hline
\end{tabular}
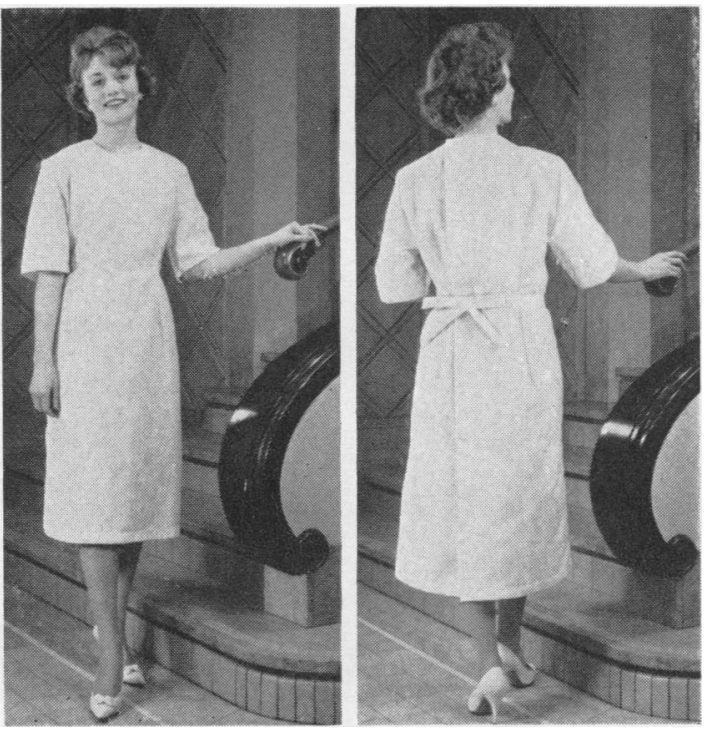

FIG. 4.-Front and back view of woman's overall.

Each time a breathing-zone sample was taken, a repeat sample was taken immediately afterwards when the operative's dusty cotton clothing had been replaced by a clean terylene overall. By ensuring
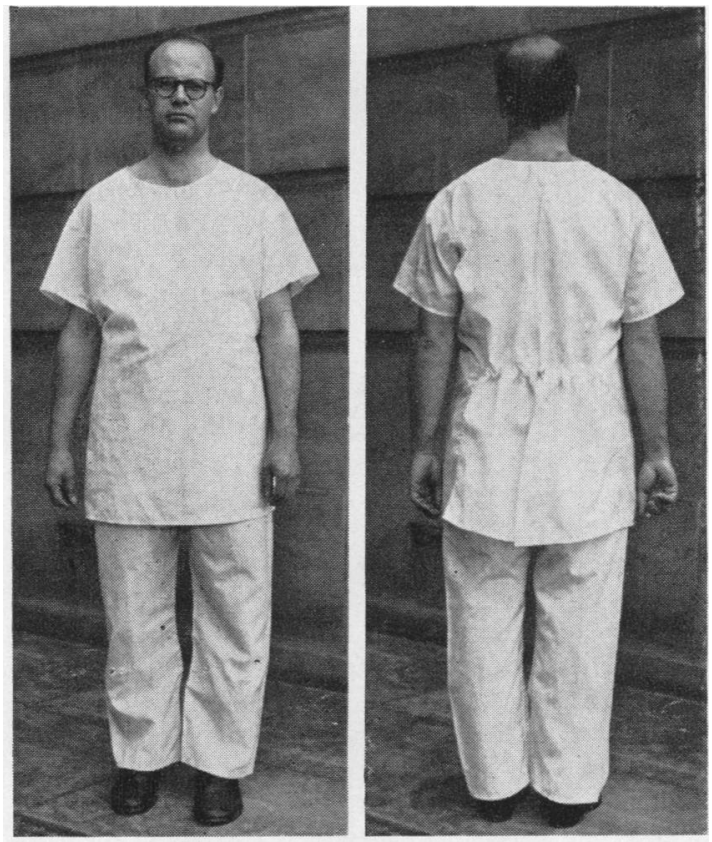

Fig. 5.-Front and back view of man's tunic and trousers. 


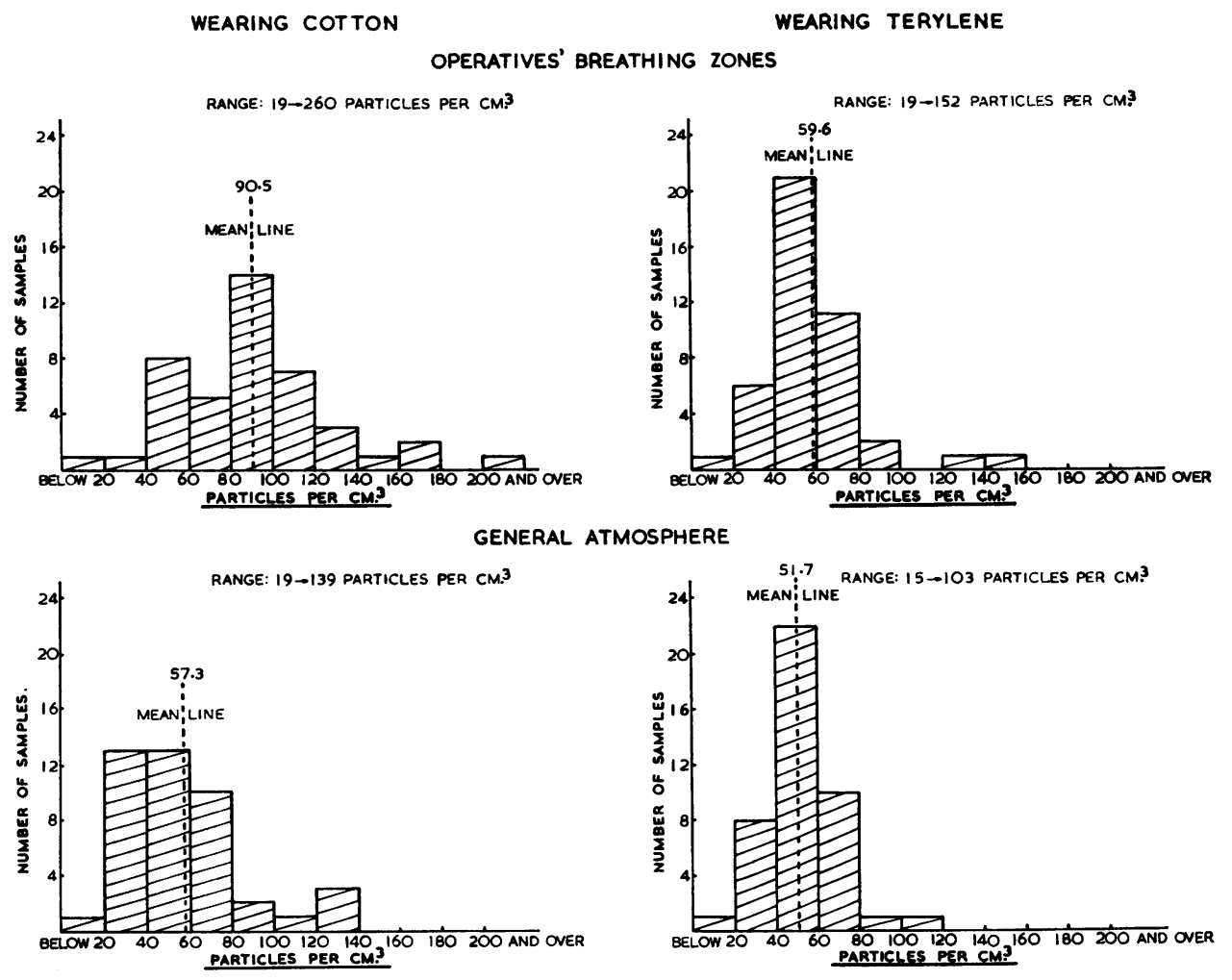

Fig. 6. - Results of dust counts. The concentrations are in particles per $\mathrm{cm}^{3}$ in the size range 0.5 to $5.0 \mu$.

that other conditions were kept as constant as possible it was hoped to assess the part played by clothing dust in the operative's dust exposure.

A total of 43 operatives were tested in this way, each sample being taken over a continuous period of about an hour. Simultaneously, samples were taken of the dust in the general atmosphere of the shop in the vicinity of the operative. The results of the dust counts are shown in Fig. 6, concentrations being in terms of particles per $\mathrm{cm}^{3}{ }^{3}$ in the size range 0.5 to 5.0 microns. For three of the operatives the dust concentrations were slightly higher when wearing terylene. The remaining $\mathbf{4 0}$ operatives showed reductions in dust concentrations of up to $65 \%$, the mean reduction for all operatives being $34 \%$.

The dust in the breathing zone of earthenware makers originates from many different sources. It is composed of the dust contained in the general atmosphere in the vicinity together with a variable proportion of dust which enters the breathing zone from purely local sources. There are often several different local sources associated with the making operation in addition to dust from dried clay on hands, arms, and clothing. Some of the local sources of dust have yet to be controlled but the fact that a mean reduction of $34 \%$ in the breathingzone concentration of these operatives can be obtained merely by changing from a dusty overall to a clean one demonstrates the importance of clothing dust in this process.

\section{Conclusions}

It is considered that the experiments described above establish that (a) cotton protective clothing is a serious source of dust; (b) treatment of cotton is not likely to provide an effective remedy; (c) among new materials, terylene has outstanding properties; and (d) provided that the type of terylene and the design of the garments are defined, substantial reduction can be achieved in the dust concentrations in the breathing zone of the operative. 
As a result of this work the Joint Standing Committee for the Pottery Industry has recommended that terylene protective clothing should be introduced for all workers engaged in pottery processes in which pneumoconiosis occurs. We present these findings in the hope that they may prove useful to other industries in which similar problems arise.

We should like to express our thanks to the Director of Research, The British Ceramic Research Association,
Dr. N. F. Astbury, for permission to publish this paper, and to a number of our colleagues who have helped with the experimental work. We are indebted to the managements of a number of factories which provided facilities for trials to be held and measurements to be taken, and also to many firms that supplied fabrics.

\section{REFERENCES}

Harwood, F. C., Powney, J., and Edwards, C. W. (1944). Brit. med. $J ., 1,615$.

Van den Ende, M., and Thomas, J. C. (1941). Lancet, 2, 755. 